\title{
Tourism Pressure in the Top Destinations in Romania
}

\author{
Iulian Adrian Sorcaru \\ isorcaru@yahoo.com
}

Dunarea de Jos University of Galati, Romania

\begin{abstract}
Romania has registered a steady increase in tourist arrivals in the last decade, benefiting from the online promotion, national and international events, but especially from low prices compared to other international destinations. Thus, most of the foreign tourists consider Romania a cheap tourist destination. The study analyzes and maps the evolution of tourism density in the last decade in the most visited tourist destinations in Romania, according to National Institute of Statistics in Bucharest and tripadvisor 2018 traveler's choice (top 10), in order to identify the effects of tourism pressure and to propose a series of measures to limit the negative effects of "overtourism" that could affect Romania in the future. The research was achieved using the data provided by the National Institute of Statistics, as well as the information present in a series of studies and websites mentioned in the references.
\end{abstract}

Key words: tourism pressure, Romanian top destinations, tourism issues, overtourism

Jel Code: Z30, Z32

\section{Introduction}

The growing tourism pressure causes the dissatisfaction that occurs among the resident population of tourist destinations. Based on forecasts of tourist arrivals around the world, this phenomenon has become a feature of the daily life of local communities and is a huge challenge for current and future generations, requiring careful reflection to limit the social and political negative impact and identifying practical solutions in the near future.

Global forecasts show that the number of tourists will rise from 940 million in 2010 to 1.8 billion in 2030, Europe being the leader of this tourism boom, with nearly half of the arrivals.

\section{Figure 1. The Projection of Tourist Arrivals (millions), By Continents}

(source: WTO Panorama on International Tourism, 2017)

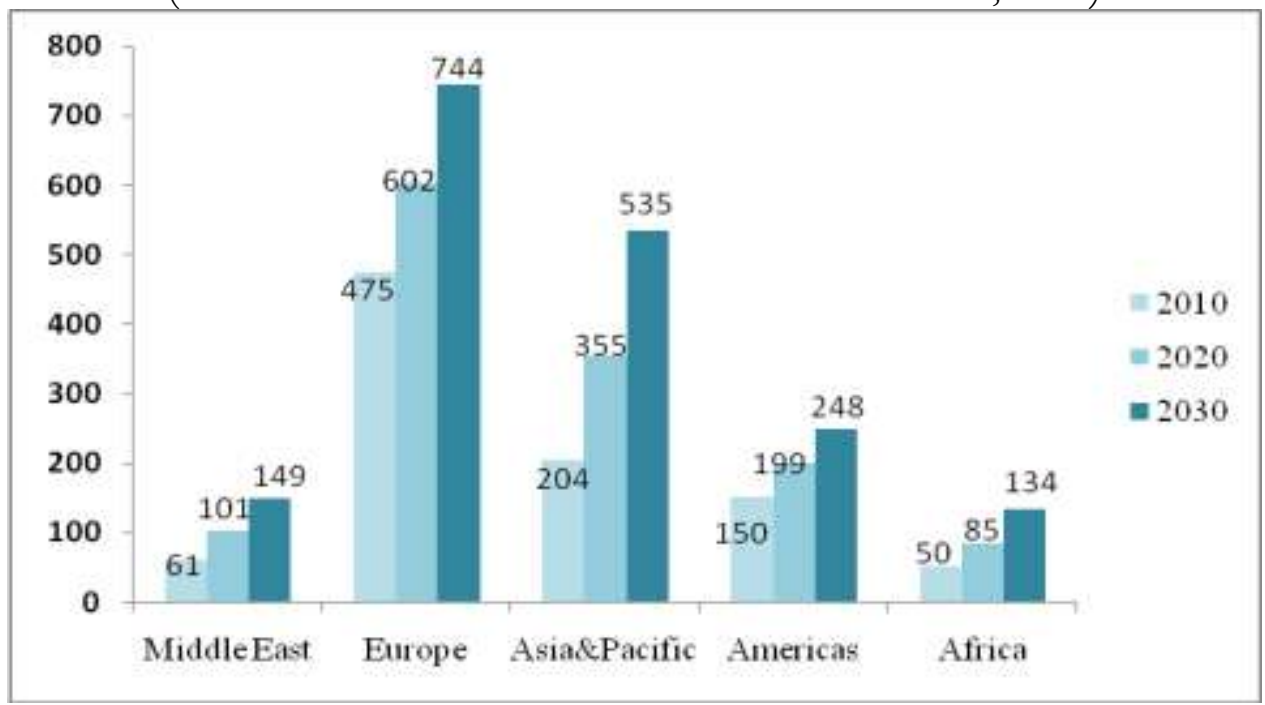


In several popular tourist destinations the occupation and privatisation of public spaces generated different kinds of protests. Starting with tourist cities such as Venice, Barcelona or Amsterdam and increasingly in cities accustomed to less tourism, destinations in Europe have seen a clear rise in the politicization of what had previously been a minor issue in urban policies: tourism. Overtourism or tourism saturation has become a problem for all agents directly or indirectly involved in the apparatus of tourism: public agents, private sectors, tourists and residents (Milano, 2017).

Romania, along with other tourist destinations in Eastern Europe, has recorded a continuous increase in tourist arrivals over the last decade, which has implicitly led to an increase in tourism pressure with obvious economic and social implications for local communities. Although, nowadays, the size of the inbound tourist flows, especially the number of foreign tourists, is low, in the future, with the increase of online tourist promotion and the development of tourism infrastructure, tourism pressure could turn quickly into overtourism.

Figure 2. Tourist Arrivals and Receipts in Europe, Change By Region, 2017 (\%) (source: UNWTO Tourism Highlights, 2018 Edition)



\section{Brief Literature Review}

Tourism pressure, reflected both by the evolution of tourist flows and by tourism density, influences the level of economic development of a region, having also a strong social impact on local communities.

The generic product life-cycle concept (PLC) predicts a decline phase after the maturity of a particular market and/ or sector. The PLC concept was adapted by Butler (TALC) for tourist areas since 1980 and it has been frequently-applied to explain the evolution and implications of tourism in destinations. According to TALC concept, each tourist destination can be found in one of the following phases (Papathanasis, 2017):

* Exploration, characterized by a small number of adventure-seeking visitors, limited information and infrastructure. In this stage, some locals may feel uncomfortable with tourists. 
* Involvement, when local community discovers its potential and participates in the development of tourism by developing basic infrastructure (i.e. small accommodation and catering facilities).

* Development, generated by local authorities and investors who notice the large number of tourist arrivals and initiate larger-scale and more sophisticated infrastructure projects.

* Consolidation, when big companies enter the competition and larger units replace small facilities. This is the start of mass-tourism. Locals feel overwhelmed with the increasing tourist numbers and the impact of developments in their daily lives.

* Stagnation appears when the destination has lost its novelty status, the tourist numbers are stabilised and the area has reached its carrying capacity. Locals are negatively predisposed and antagonistic towards the tourists.

* Decline phase, when the environmental and socio-cultural externalities of tourism development begin to show and degradation of the destination's resources and infrastructure drives visitors away. The irritation of locals becomes even more evident.

Most studies that analyze international tourism pressure, are focused on tourist destinations found in the "consolidation phase", using the concept of "overtourism" and studying the negative socio-economic impact on the resident population. Overtourism has been manifested in the last decade, especially in urban regions of Europe, in the capital cities or those with a remarkable cultural patrimony.

Overtourism specifically manifests itself in two key ways:

$\checkmark$ the spread of urban tourism to residential neighbourhoods that were not previously visited much by tourists;

$\checkmark$ transformation and changes in the everyday lives throughout the neighbourhoods.

Also, public transportation, infrastructure, roads, museums, attractions and other services that were primarily created for local use suffer under increasing tourist numbers. The growing popularity of online accommodation services (e.g., AirBnB, HomeAway, Uber) and a desire to see 'real' and 'authentic' everyday city life has meant that tourism activities become further intertwined with local life, also outside of the main tourist areas in cities (Pappalepore, I.; Maitland, R.; Smith, A., 2014). Such developments have led to an increasingly vocal call from residents and local stakeholders to deal with tourism growth and protests have been observed in multiple high profile destinations (e.g., Barcelona, Venice). Although the issue is most prominent in European cities, similar sentiments have been reported in other destinations too, for example tropical islands, backpacker ghettos, or even slums (Koens, K.; Thomas, R., 2016).

The most popular and visited tourist destinations in Romania, especially those from urban areas, are currently under the TALC concept, in the involvement phase, but as we will see from the study results, tourism pressure in the last decade registered an upward trend, and the effects specific to overtourism, though incipient at this time, have begun to manifest: overcrowding in city's public spaces, pervasiveness of visitor impact due to inappropriate behavior, physical touristification of city centers and other often visited areas, pressure on local environment, higher rents due to AirBnB platform.

\section{Objectives And Methodology}

The upward tourism demand in the last decade, especially for the European destinations, also characterizes, as we have seen in the introduction, certain countries of Central and Eastern Europe, which are not part of mass tourist destinations, but are still able to attract an increasing number of tourists. Thus, the study is focused on the following major objectives:

$>$ identifying the first ten tourist destinations (tourist centers) in Romania, according to the number of tourists in 2017 and their comparison with the top achieved in 2018 by one of the most popular travel websites worldwide, tripadvisor.com, based on the destinations in Romania, preferred by foreign tourists; 
> calculating the tourism density and mapping the evolution of tourism pressure during 2007-2017 for the most visited tourist destinations in Romania;

$>$ identifying the socio-economic effects generated by the increase of tourism pressure;

$>$ proposing measures to limit the negative effects of a possible "overtourism" in the future

The evolution of the tourism pressure on the most visited tourist destinations in Romania was calculated using the tourism density index, useful in the elaboration of the territorial and social tourism policy. Being aware of the unfavourable demographic evolution in Romania, characterized by a significant depopulation process over the last two decades, we considered that the most relevant index for reflecting the evolution of the tourism pressure is the index of the tourism density in relation to population $\left(\mathrm{TP}_{\mathrm{p}}\right)$ :

$$
\mathrm{TP}_{\mathrm{p}}=\mathrm{T} / \mathrm{P} \times 100
$$

T-tourist arrivals; P- inhabitants of tourist destination

Therefore, we have calculated this index in 2007, 2012 and 2017, a period that has elapsed since Romania's accession to the European Union. The research was conducted using the information provided by relevant institutions and international websites, including the UNWTO (World Tourism Organization), Tripadvisor, INS (National Institute of Statistics, Romania), as well as studies from the literature mentioned in the references.

\section{Results}

The most visited tourist destinations in Romania in 2007, 2012 and 2017, according to the statistics provided by INS, as well as the international websites, remain the urban ones, some of them registering an increase of $100 \%$ in the number of tourists during the analyzed period (Figure 3). As we can see, the top ten favorite holiday destinations in Romania are clearly dominated by Bucharest, being followed by the cities of Brasov, Constanta, Cluj-Napoca, Sibiu, Timisoara, Sinaia, Iasi and Oradea, each of them having more valuable cultural attractions compared to other urban regions in Romania. The only surprise, by positioning in the middle of the top (6th place in 2017), is Mangalia, a city whose tourist valences have always been generated by seaside tourism at the Black Sea. At the same time, according to one of the most famous international sites (tripadvisor.com) the foreign tourists who visited Romania in 2018, preferred almost the same destinations except for Suceava, which replaces Mangalia. (https://www.tripadvisor.com/TravelersChoice).

The tourism pressure in these urban regions in Romania, has also been steadily increasing for most of the destinations due to the increase in tourist arrivals and also to the demographic decrease (figure 4). In some cases the values of the tourism pressure are spectacular, Sinaia registering $2580,3 \%$ in 2017 . Also, with only a few exceptions, almost all of the top ten urban tourist centers have a tourism pressure that exceeds $100 \%$ or approaching this rate in 2017. 
Figure 3. Most Visited Destinations in Romania By Tourist Arrivals During 2007-2017 (source: INS, Romania, Tempo-Online Database)



Figure 4. Tourism Pressure in the Most Visited Destinations In Romania in 2017

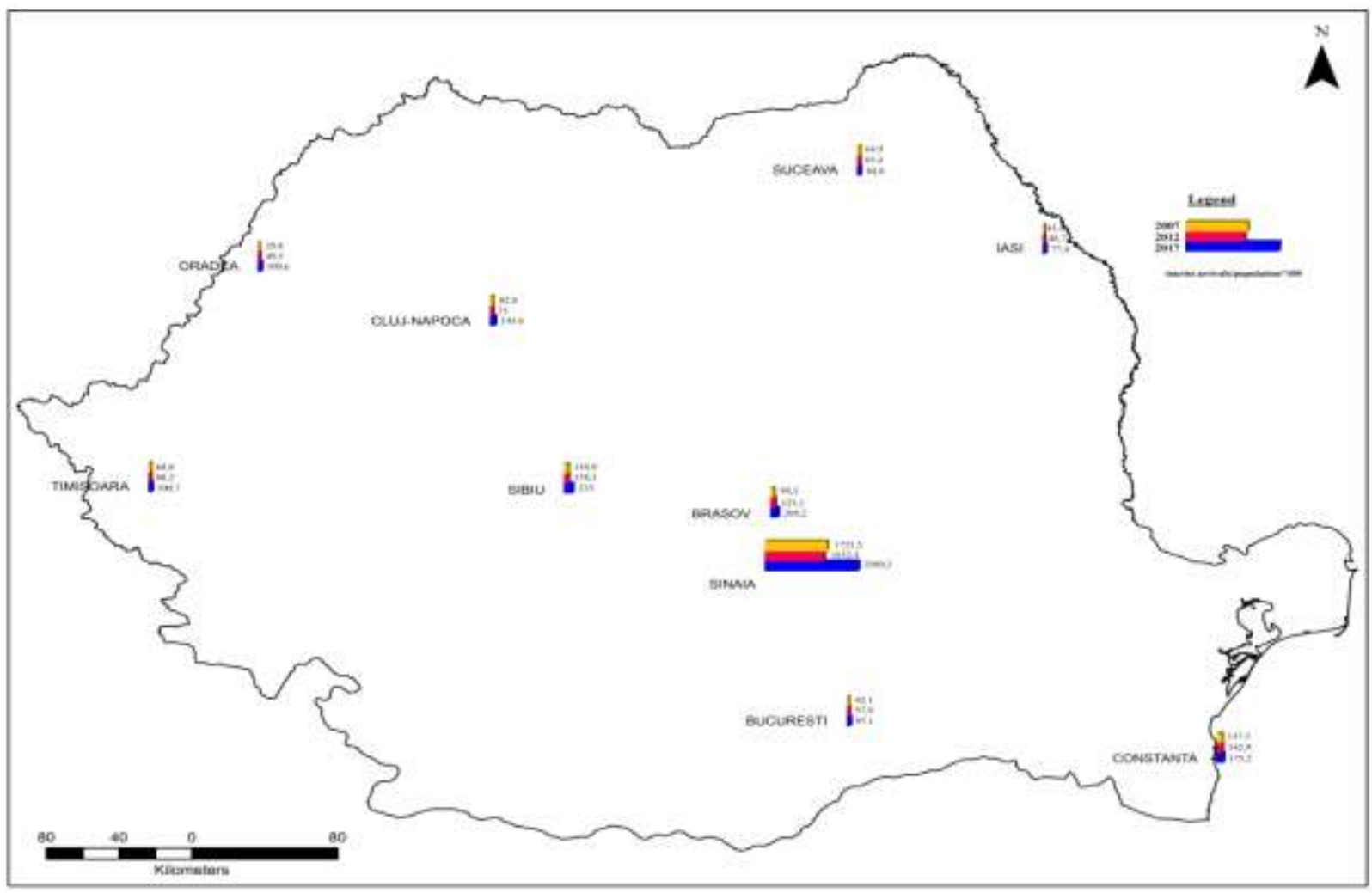

(source: map made in ArcGis 10.1, data calculated using Tempo-Online Database, INS, Bucharest)

The immediate effect of the increased tourism pressure in the most visited urban destinations in Romania was the extension of urban tourism to marginal districts, which were not visited in the past by tourists, which in the near future may have an impact on the daily life of the resident population. This effect was also strongly influenced by the fact that, the number of 
accommodation places, offered by city residents who rented their apartments on certain online platforms (Airbnb is the most evident example) has also increased.

At the same time, another effect that may have unfavourable consequences, especially for the residents who pay rent, but also for the ones who want to buy a property in these cities where the tourism pressure is constantly increasing, is the substantial raise of the average rental and sale prices of real estate properties.

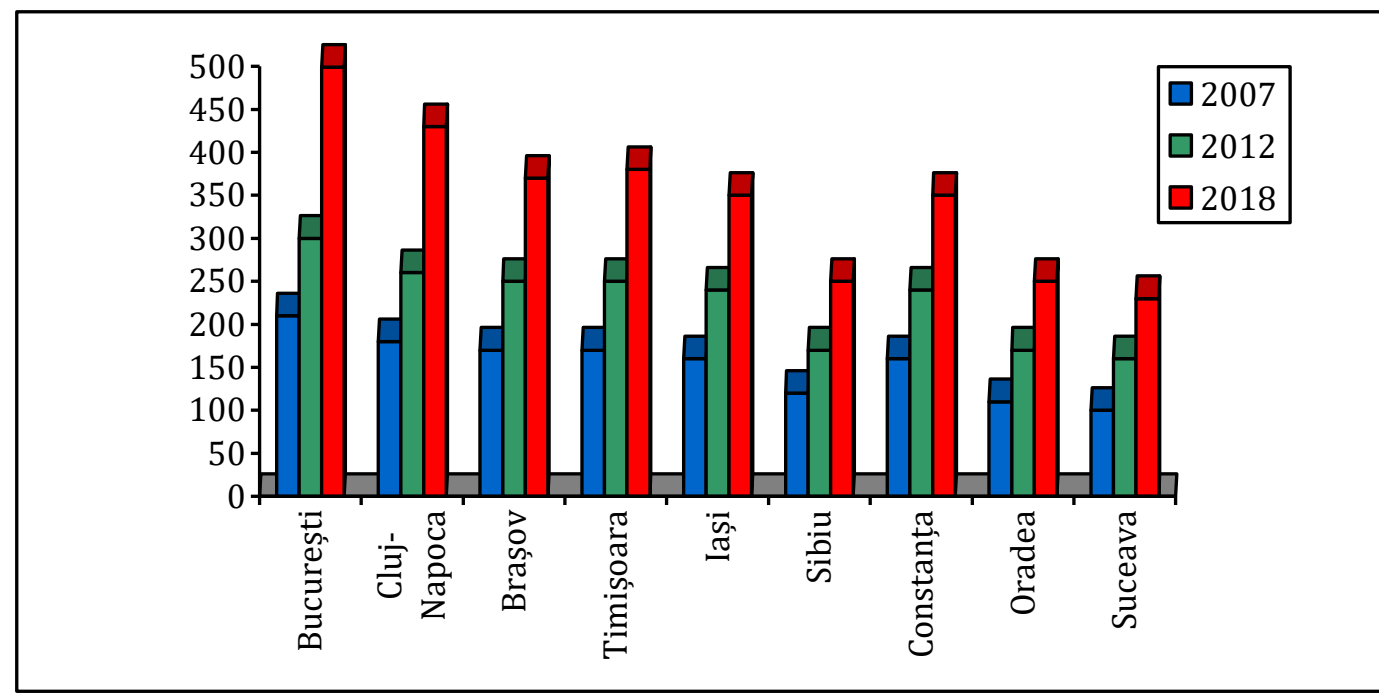

Figure 5. The Evolution of Average Rental Prices in The Most Visited Destinations In Romania During 2007-2018 (source: imobiliare.ro)

Other negative effects, visible in recent years, especially in the historical center of Bucharest, generated by the increase in tourist arrivals, are the changes in the local identity and value system, caused by changes in the structure of demand for goods and services, standardization and dilution of the authenticity. Thus, fulfilling the expectations and desires of tourists, the local population started to transform cultural customs and traditions into commodities, and objects and places with an ethnic load lose their significance as they become goods for sale. Fast food restaurants, certain bars, international restaurants (Turkish, Irish, German) and/or shops located close to tourist attractions in the center of Bucharest can change in time the authenticity of the historic center.

\section{Conclusions}

The upward tourism pressure is preceding the overturism and tourismphobia phenomena in most cases, and Romania, especially the urban tourist destinations served by airports, has in recent years recorded all the prerequisites for increasing the tourism density in the future. At this moment, the effects of increasing tourism pressure in Romania are incipient, the growth of tourist arrivals, especially international ones, being encouraged by accelerating some investments that can improve tourist accessibility (motorways, modernization of airports), but also by promotion at national and international events and online. However, beyond the positive effects of tourist arrivals, especially international ones, in the future, there is a high possibility to witness a migration of tourismphobia and overtourism from certain destinations in central and western Europe to the east ones, including Romania, which requires awareness and adoption of policies to limit the negative effects of central and local authorities.

\section{References}

Milano, C., 2017), Overtourism and Tourismphobia: Global trends and local contexts, Barcelona: Ostelea School of Tourism \& Hospitality 
Pappalepore, I.; Maitland, R.; Smith, A. (2014), Prosuming creative urban areas. Evidence from East London. Ann. Tour. Res. 2014, 44, 227-240.

Papathanassis, A., (2017), Over-Tourism and Anti-Tourist Sentiment: An Exploratory Analysis and Discussion, "Ovidius" University Annals, Economic Sciences Series Volume XVII, Issue 2 / 2017

Koens K.; Postma A.; Bernadett P., (2018), Is Overtourism Overused? Understanding the Impact of Tourism in a City Context, Sustainability 2018, 10, 4384

Koens, K.; Thomas, R. , (2016), You know that's a rip-off: Policies and practices surrounding micro-enterprises and poverty alleviation in South African township tourism. J. Sustain. Tour., 24, 1641-1654.

*** World Tourism Organization, (2018), UNWTO Tourism Highlights, 2018 Edition, UNWTO, Madrid *** https:/ / mww.tripadvisor.com/TravelersChoice

*** bttp:/ / statistici.insse.ro:8077/ tempo-onlinel

*** https: / / wnw.imobiliare.ro/ 